\title{
NARRATIVAS INTERATIVAS E JOGOS DIGITAIS: CONSIDERAÇÕES SOBRE FORMAS DE ESCRITA, LEITURA E IMERSÃO
}

\author{
Francisco Carlos de Carvalho Marinho*
}

\begin{abstract}
RESUMO: Este artigo busca levantar algumas considerações sobre textos narrativos digitais interativos e jogos digitais interativos, referindo-se ao processo de produção participativa, à massificação do acesso a essas obras na Web e a sua importância para o campo da educação e da arte. O texto aborda características transdisciplinares de processos de escrita digital, incluindo o conceito de fluxo defendido por Mihaly.
\end{abstract}

PALAVRAS-CHAVE: Narrativas interativas. Livros e jogos digitais. Fluxo. Educação, arte e entretenimento.

Crawford (2014) considera o fenômeno de contar histórias (storytelling) consequência quase inevitável da evolução humana. $O$ autor argumenta que módulos mentais específicos foram desenvolvidos e favoreceram os hominídeos na tarefa de resolver problemas. As consequências da mudança filogenética propiciaram a emergência da linguagem, que alterou dramaticamente o modo como as nossas mentes funcionam, permitindo comunicação complexa entre entes de mesma espécie. Crawford considera ainda que as estórias em volta da fogueira se tornaram uma espécie de "kitten play" para os humanos como forma de preparação e educação para sobrevivência.

Se do ponto de vista fisiológico/antropológico a linguagem permitiu uma capacidade especial de interação do homem com o mundo, as tecnologias de informação, centenas de milhares, ou milhão, de anos depois, computação e comunicação propiciaram, de modo parecido, mudança tremendamente brusca na relação do homem com o ambiente e com seus semelhantes por meio de "linguagens" múltiplas, incluindo-se os códigos computacionais. Quanto a estes, Reas (2010) chama a atenção para três propósitos diferentes:

\footnotetext{
“Universidade Federal de Minas Gerais, Belo Horizonte, Brasil. Imeio: chicomar@uol.com.br

${ }^{1}$ Brincadeiras que gatos fazem como "educação" para o enfrentamento dos problemas sobrevivência.
} 
comunicação, clarificação e, ainda, ocultação (no sentido de criptografar, esconder e limitar a leitura). Notadamente podemos perceber que linguagem é poder.

Existe ainda, relativamente ao que é produzido, muito pouco material teórico e crítico que faça análises sobre as possibilidades e potencialidades das narrativas interativas, as quais abrangem um vasto campo de disciplinas de natureza distintas. Sobre isso, Crawford (op.cit. posição 193 de 6690) afirma que "narrativas interativas" é um campo novo concebido no final dos anos 80 , experimentado no começo dos anos 90 e somente por volta de 2010, reconhecido um campo de conhecimento relevante, quer seja sob o ponto de vista da prática e experimentação como da perspectiva teórica. Ainda segundo o autor, a pluralidade de perspectivas sobre o assunto é grande, desde cineastas que enxergam as narrativas interativas como uma forma de cinema, a game designers que reclamam a propriedade da disciplina para si, e ainda cientistas da computação que veem como um campo mais aberto da inteligência artificial e experts em artes midiáticas e digitais que se apropriam do tema de outra forma. Na realidade, os campos se fundem de tal modo que um designer, por exemplo, deve entender de programação, jogos, design de interfaces, matemática, interação homem computador, psicologia comportamental e cognitiva entre tantos outros. O campo de conhecimento é realmente multi e transdisciplinar, ressaltando, para nosso escopo, a ênfase em campos como a comunicação, a arte e a educação.

Necessário dizer ainda que, quando falamos em narrativas interativas, grande parte da novidade e do entendimento do fenômeno reside na qualificação das narrativas como sendo interativas, ou melhor, que a interatividade é um imperativo categórico dessas narrativas em meios digitais. Se a interação é importante, mais ainda o papel do usuário, que passa de leitor passivo a coautor, na medida em que altera os plots da narrativa e modifica seu sentido. Segundo Aarseth (1997), o papel do leitor nas narrativas que podemos aqui nomear tradicionais é de um voyeur, seguro, mas impotente, enquanto o leitor das narrativas interativas (ou de jogos digitais) é de um player. 
Embora o termo "narrativas interativas" tenha seu escopo definido, sob nossa perspectiva, em meios digitais, sua gênese é antiga. Miller (2004) observa que contar histórias interativamente remonta às reuniões em volta da fogueira desde os tempos pré-históricos. Para Campbell (apud Handler) a forma mais antiga de estória são os mitos e que os narradores não recitavam esses contos antigos simplesmente. A comunidade poderia reencená-los (revivê-los) na forma de rituais religiosos e ritos de passagem nos quais os participantes desempenhavam um papel ativo dentro de um contexto coletivo. Os rituais dionisíacos tinham estrutura parecida. Miller observa que essas celebrações antigas têm semelhanças com os jogos massivos multiusuários em rede (MMOGs - Massive Multiplayer Online Games) da era digital.

As estórias e histórias que contamos e construímos através de aparatos tecnológicos e cognitivos (que se situam entre o espectro de dispositivos como linguagem verbal escrita ou falada aos sistemas informáticos e robóticos) mudaram significativamente $\mathrm{o}$ modo como percebemos, atuamos $\mathrm{e}$ construímos mundos. Ficam marcadas as potencialidades estéticas e pedagógicas dessas formas de contar histórias e estórias segundo suas características próprias como meio, suporte ou conteúdo.

Ryan (2004), na Introdução de seu livro Narratives Across Media, tenta organizar as várias acepções do conceito de narrativa, as quais revelam a pluralidade de sentidos e significados dados ao termo. Embora esteja ciente da polissemia do termo, a autora procura por alguma coisa em comum que possa fundamentar esse fenômeno que ocorre em meios distintos, do livro como códex às instalações de mundos virtuais imersivos. A autora propõe duas formas de classificação de comunicação/expressão como meios de narrativas: 1) deve haver uma diferença sobre o tipo de mensagens (narrativas) que podem ser transmitidas, como elas são apresentadas e como elas são experimentadas; 2) Deve estar presente uma única combinação de características: a) os sentidos endereçados; b) prioridade entre as trilhas sensoriais; c) extensão no tempo e no espaço; d) suporte tecnológico e materialidade dos signos; e) papel cultural e métodos de distribuição/produção. 
Entre essas categorias levantadas pela autora podemos situar os livros-jogos digitais.

O conceito de livro-jogo está inserido no contexto das várias revoluções informáticas entre as quais a emergência de dispositivos computacionais portáveis (até mesmo vestíveis) capazes de veicular cultura e conhecimento com características próprias e definidas segundo suas potencialidades e restrições. De fato, a disseminação de dispositivos móveis amplia a potencialidade dos jogos digitais e outras formas de narrativas interativas como expressão cultural de diferentes naturezas, mas intrinsecamente articuladas e emaranhadas. As formas de escrita (produção) e leitura (uso) introduzidas por essas tecnologias estão mudando a forma como dizemos e percebemos 0 mundo. O livro impresso ainda permanece como uma tecnologia de comunicação e expressão dominante, principalmente no meio acadêmico, mas talvez essa prevalência esteja com os dias contados. Difícil compreender os motivos pelos quais ainda não nos utilizamos de toda a potencialidade das hipermídias na produção e divulgação de conhecimento, mesmo depois de Vannevar Bush haver idealizado o Memex há décadas e a computação ter favorecido sua realização, ainda que de outras formas. Essa defasagem talvez tenha algumas de suas raízes nas dificuldades econômicas e sociais que dificultam o acesso ao conteúdo a um público mais amplo. Entretanto, em meio acadêmico o uso das hipermídias ainda é uma dificuldade em função talvez da dificuldade de produção/escritura. Em países com altíssimo desenvolvimento tecnológico a situação parece ser um pouco diferente. Em matéria divulgada no site $\mathrm{UOL}^{2}$, a Coréia do Sul tem planos de substituir nas escolas os livros impressos por livros eletrônicos até 2015. Não defendemos incondicionalmente, a partir dessa iniciativa coreana, a substituição de um sistema por outro, apenas registramos o fato de que a escrita hoje ganha novos recursos e potencialidades, mas não necessariamente mais rica em função das tecnologias de ponta disponíveis. O domínio da escrita hipermidiática interativa ainda não está inteiramente consolidado. A história é testemunha de que as tecnologias automatizadas de comunicação que emergiram ao longo de pouco

\footnotetext{
2. Disponível em: <http://gizmodo.uol.com.br/nada-de-papel-ate-2015-todos-os-livros-escolaresserao-digitais-na-coreia-do-sul/>. Acesso em: 05 ago. 2013
}

Texto Digital, Florianópolis, v. 10, n. 1, p. 138-162, jan./jul. 2014. ISSNe: 1807-9288 
mais de um século como a fotografia, o cinema e a televisão não capitularam com o surgimento da Internet, nem mesmo os textos escritos foram substituídos por mídias audiovisuais. Entretanto podemos afirmar que o espaço de fase ou o campo de possibilidades das mídias digitais interativas é mais amplo, pois inclui grande parte de todos os anteriores e acrescenta os seus próprios. As textualidades fortemente imagéticas, graças às tecnologias midiáticas audiovisuais da era anterior ao digital, construíram outros discursos possíveis os quais seriam impossíveis ao texto primordialmente escrito. $O$ material gerado por pesquisas e estudos de diferentes matizes sobre comunicação verbal e não-verbal nas mídias audiovisuais é vasto e profundo, embora ainda longe de esgotar o assunto. Sempre surgem novas perspectivas. No campo das mídias digitais os textos possíveis se ampliaram em extensão e natureza. Os estudos sobre as formas midiáticas emergentes de organizar o mundo ainda são incipientes se compararmos com os estudos sobre o texto tradicional nos campos da semiótica, linguística, análise do discurso, teoria da literatura e outras tantas áreas que se ocupam da matéria em questão. Embora a compreensão dos processos e fenômenos inerentes aos textos digitais ainda mal tenha começado, e é nesse contexto que nossa pesquisa se insere, a produção já alcança patamares elevados, tanto em quantidade quanto em qualidade. As ferramentas disponíveis permitem aos iniciados nas tecnologias de informação e comunicação produzir, com relativa rapidez, as obras de grande complexidade no processo de autoração. Observamos que o trabalho de autoria muda radicalmente das mãos de um único autor (como era 0 costume) para coletivos que trabalham colaborativamente. O letramento digital ainda não alcançou o topo da academia. Os professores mais antigos ainda não se apropriaram eficientemente das formas de produção de leitura e escrita digital interativa. Em uma geração a mudança dramática de paradigma textual produziu um abismo cultural entre o que Prensky ${ }^{3}$ (2001) denomina nativos digitais e imigrantes digitais. Grande parte dessa diferença cultural nasce na prática e na difusão de jogos digitais propiciadas pelos computadores pessoais.

\footnotetext{
${ }^{3}$ PRENSKY, Marc. Digital Natives, Digital Immigrants. NCB University Press, v. 9, n. 5, October 2001). Disponível em: $<$ http://www.nnstoy.org/download/technology/Digital\%20Natives\%20\%20Digital\%20Immigrants.pdf >. Acesso em: 05 ago. 2013
} 
Todo um sistema novo de produção de conhecimento deve ser repensado em função das novas tecnologias de conhecimento. Prensky (idem, p.2) diz:

[...] But this is not just a joke. It's very serious, because the single biggest problem facing education today is that our Digital Immigrant instructors, who speak an outdated language (that of the predigital age), are struggling to teach a population that speaks an entirely new language. (Grifos originais)

O fato é que a velocidade das mudanças é cada vez mais rápida. As tecnologias da inteligência colocam à disposição de autores formas, processos, ferramentas, sistemas e dispositivos de produção textual cada vez mais sofisticados. LÉVY $(2000$, p. 28) enfatiza a taxa de variação da velocidade de transformações ocorridas pelo fator digital.

A aceleração é tão forte e tão generalizada que até mesmo os mais ligados encontram-se, em graus diversos, ultrapassados pela mudança, já que ninguém pode participar ativamente da criação das transformações do conjunto de especialidades técnicas, nem mesmo seguir essas transformações de perto.

Entretanto mudança de hábitos não é algo trivial em idades mais avançadas e é muito diferente de adquiri-los nas idades mais adequadas. Enquanto os nascidos na idade digital não encontram obstáculos cognitivos ou psicológicos na lida com os mundos virtuais, como o medo e a ansiedade, os "imigrantes" têm variados graus de dificuldade. Isso se reflete clara e indubitavelmente nas instituições acadêmicas e escolas, públicas ou privadas, e em algumas instituições de fomento à pesquisa. Sobre isso, Lévy ${ }^{5}(1993$, p.86) comenta:

É certo que a escola é uma instituição que há cinco mil anos se baseia no falar/ditar do mestre, na escrita manuscrita do aluno e, há quatro séculos em uso moderado da impressão. Uma verdadeira integração da informática (como do audiovisual) supõe portanto o abandono de um hábito antropológico mais que milenar, o que não pode ser feito em alguns anos.

\footnotetext{
${ }^{4}$ LÉVY, Pierre. Cibercultura. São Paulo: Editora 34, 2000.

${ }^{5}$ LÉVY, Pierre. As Tecnologias da inteligência. O Futuro do pensamento na era da informática. São Paulo: Editora 34, 1993.
} 
Já se passaram 20 anos da publicação deste texto de Lévy. Os imigrantes digitais vão se tornando cada vez mais escassos. Entretanto, eles ainda ocupam nas instituições cargos decisórios e podem atrasar a demanda por pesquisa e entendimento do fenômeno digital que os coloca frente aos problemas os quais ainda não têm a dimensão do impacto cultural. Mas a pressão da sociedade que se informatiza é grande. Para termos uma ideia bem clara e distinta das proporções épicas do uso cultural das mídias digitais vale a pena citar alguns dados que nos obrigam a olhar de outro modo para a questão dos jogos digitais (narrativas interativas) no que toca aos hábitos contemporâneos. Castronova ${ }^{6}$ (2007, segundo McGonigal $^{7}$, 2012, posição 91 de 7154) fala de um êxodo massivo dos "gamers" que partem da "realidade" para o mundo digital. Afirma o economista que só nos Estados unidos já são 180 milhões de jogadores ativos que passam mais de treze horas por semana jogando. McGonigal cita várias fontes e levanta números impressionantes sobre aqueles que "deixaram a realidade" para viver o mundo dos jogos: 10 milhões de jogadores na Rússia, 105 milhões na Índia, 10 milhões no Vietnã, 13 milhões na América Central e na América do Sul, 15 milhões na Austrália, 17 milhões na Coréia do Sul, 100 milhões na Europa e 200 milhões na China. McGonigal (Ibdem, posição 265 de 7154) fala de uma massa de jogadores nos Estados Unidos composta de:

- 69 percent of all heads of household play computer and video games.

- $\quad 97$ percent of youth play computer and video games.

- 40 percent of all gamers are women.

- One out of four gamers is over the age of fifty.

- The average game player is thirty-five years old and has been playing for twelve years.

- Most gamers expect to continue playing games for the rest of their lives.

A autora destaca ainda que essa indústria fatura $U \$ 68$ bilhões de dólares ao ano, base em 2012, e com clara tendência ao crescimento acelerado. Esses levantamentos foram feitos sem contar o mercado paralelo que é gigantesco.

\footnotetext{
${ }^{6}$ CASTRONOVA, Edward. Exodus to the Virtual World (New York: Palgrave Macmillan, 2007), xiv-xvii. This condensed passage from the preface appears with the permission of the author.

${ }^{7}$ MCGONIGAL, Jane. The Reality is Broken. Why Games Make us Better and How They Can Change The World. New York: Penguin Press, 2012.
} 
Coletivamente, são 3 bilhões de horas jogadas semanalmente no mundo inteiro por usuários regulares. Como ignorar a importância desses números? Como ignorar o poder de sedução e o prazer gerado por esses conteúdos que talvez sejam a expressão cultural mais importante de nossa época? Como deixar de compreender as formas colaborativas e interativas de contar estórias e histórias? E, mais ainda, como ignorar as possibilidades de aplicação dos processos de escrita e leitura das novas narrativas digitais aos processos de produção e difusão do conhecimento? Mas observar o impacto econômico é apenas uma faceta do problema. Trata-se de uma revolução cultural que deve ser entendida em todas suas dimensões disciplinares, multidisciplinares e transdisciplinares. É urgente abordar o grande mundo digital dos jogos de uma perspectiva séria e científica, muito embora alguns acadêmicos ainda insistam em falar "joguinhos" pejorativamente. Conjecturando, mas levando em consideração pesquisas na área, talvez o "medo intelectual" seja o componente mais presente nas objeções, às vezes irracionais, dos apocalípticos, que em sua grande maioria nunca experimentaram jogar e vivenciar os mundos digitais. A prática da escrita desses jogos digitais realizada pelos nativos e até mesmo imigrantes digitais se faz eloquente o bastante para que as ciências cognitivas olhem para o fenômeno sem restrições a priori. $\mathrm{Gee}^{8}(2004$, p.7) fala sobre o assunto:

Of course, there is an academic field devoted to studying how human beings learn best and well, namely the field of cognitive science. So we can, then, compare the theory of learning in good video games to theories of learning in cognitive science. Who's got the best theory? Well it turns out that the theory of learning in good video games is close to what I believe are the best theories of learning in cognitive science. And this is not because game designers read academic texts on learning. Most of them don't. They spent so much of their time in high school and beyond playing with computers and playing games.

$\mathrm{Gee}^{9}$ (2013) continua argumentando sobre o aprendizado mediado por computadores e principalmente por estruturas pedagógicas altamente eficientes como vídeo games. Em seu livro The Anti-Education Era. Creating

\footnotetext{
${ }^{8} \mathrm{GEE}$, James Paul. What video games have to teach us about learning and literacy. USA: Palgrave Macmillan, 2004.

${ }^{9} \mathrm{GEE}$, James Paul. The Anti_education Era. Creating Smarter Students Through Digital Learning. USA: Palgrave Macmillan, 2013.
} 
Smarter Students Through Digital Learning, o autor questiona por qual motivo o "Homo Sapiens" poderá ser muitas vezes tão estúpido ${ }^{10}$. A estupidez é o ponto de partida de sua argumentação. Questiona muitas posições "estúpidas" tais como: fundamentalismo econômico e religioso, criacionismo, racismo, tecnologias de guerra, aquecimento global e conservadorismo educacional. Diz ainda que pesquisas têm mostrado que há uma tendência inata ("built-in mental bias") dos humanos a favorecer informações que de alguma forma reforçam nossas crenças. Gee chama a atenção para as ferramentas digitais como modo de nos tornarmos menos estúpidos e mais espertos. Entretanto, atenta ao fato de que essas ferramentas não são a salvação. Elas podem simplesmente fazer as coisas ficarem piores ou melhores. Depende do uso. Sob esse aspecto crescem os estudos na área do "design de emoções" que podem impactar (positiva ou negativamente) a maneira como percebemos uma realidade apresentada midiaticamente. Gorp (2012) fala sobre como é importante compreender o mecanismo das emoções e das percepções humanas para de design de interação e interface (jogos digitais, narrativas interativas) de modo a maximizar a experiência do usuário (jogador, leitor ou espectador). Segundo o autor a emoção colore a realidade dominando as tomadas de decisões, comandando a atenção e aprimorando a memória. As emoções estão na base dos mecanismos de atribuições de significado e produção de sentido. Um bom design de emoção pode significar um projeto pedagógico eficaz, uma comunicação eficiente ou um trabalho de arte cativante. Os designs de emoção, ou designs de comportamento, constituemse em métodos de persuasão efetivos. Emoção desperta a atenção que dirige as tomadas de decisão, afetando a maneira de raciocinar, memorizar e sentir. Não é necessário ressaltar por demais a importância dos aspectos psicológicos em narrativas interativas, principalmente nos jogos digitais que por sua vez se configuram como excelente ferramenta pedagógica. A psicologia cognitiva e

\footnotetext{
${ }^{10}$ [...] In his classic futuristic novel, 1984, George Orwell raised a particularly interesting question about us humans: why do we so often believe things that manifestly false? Orwell had in mind that ways in which totalitarian regimes can get people to firmly believe things contradicted by obvious facts. It flourishes in free societies as well. It is a human trait easily exploited by politicians, charlatans, and the media.
} 
comportamental tem um papel central nas formas de comunicação interativas e responsivas.

Evidentemente que compreender essas escrituras digitais pode contribuir para diminuir o enorme abismo intelectual que se criou com o advento dessas mesmas escrituras. Depende das instituições de ensino e pesquisa, das escolas, dos profissionais, e das pessoas comuns se interessem em aprimorar o potencial criativo das mídias digitais. Ressaltamos o papel das instituições de ensino e pesquisa em fomentar o desenvolvimento de nossas potencialidades, habilidades e capacidades criativas.

McGonigal (2012) afirma que se a criatividade dos jogadores para resolver problemas do mundo virtual fosse canalizada para o mundo real já teríamos solucionado grande parte deles. Falamos de problemas complexos, inclusive aqueles que se encaixam em categorias que Casti $^{11}(1998)$ afirma não ser possível verificar empírica e repetidamente, ou seja, fenômenos tais como: tendências de bolsa de valores, epidemia em grandes cidades, aquecimento global, explosões atômicas etc. Evidencia-se nesses casos mais uma característica das textualidades digitais que é a simulação, a capacidade de produzir mundos virtuais - que são modelos (abstrações) experimentáveis da realidade. Existem vários jogos, como o Clássico Sim City de Will Wright, cujo gênero de simulação ajuda as pessoas a compreender, por exemplo, o gerenciamento de uma grande cidade, através de ações efetivas em um mundo hipotético. Ressaltamos ainda que se a experiência do usuário for maximizada em termos de atenção e engajamento, maior será a probabilidade de suas respostas serem propositivas e criativas.

Compreender a emergência do fenômeno mundial que é o tempo gasto em jogos digitais por um número tão significativo de pessoas psicologicamente envolvidas, em tão pouco tempo de história, é algo urgente e imprescindível. Isto é compreender a civilização contemporânea a partir de seus hábitos e ações induzidos por nada mais nada menos do que estórias interativas. Como ignorar essa massa humana que começa a aprender em outras modalidades

${ }^{11}$ CASTI, John L. Mundos Virtuais. Como a computação está mudando as fronteiras da ciência. Rio de Janeiro: Revam, 1997. 
de leitura? McGonigal (op. cit.) afirma que os jogos digitais têm dado à sociedade suas necessidades genuinamente humanas. Os jogos estão dando recompensas (psicológicas e emotivas) que a realidade não dá. Os jogos nos têm ensinado, inspirado e engajado de uma maneira diferente, que a realidade não consegue alcançar, além de nos colocar juntos colaborando mutuamente para resolução de problemas que propomos a nós mesmos com intuito de diversão, entretenimento e arte. Para McGonigal, game design não é uma mera habilidade intelectual tecnológica, mas uma nova forma de pensar (escrever e ler) que nos faz trabalhar coletivamente na solução de problemas, problemas estes que poderiam ser da realidade mesma. Se todo este esforço feito por jogadores (como jogar 3 bilhões de horas por semana), para resolver problemas de mundos virtuais fosse canalizado para resolver problemas reais 0 mundo seria outro, reflete a autora. Jogos digitais e narrativas interativas estão para a sociedade contemporânea como os livros estiveram para as gerações pós-imprensa: uma reestruturação fundamental nos processos de escrita e leitura, ainda que com características completamente diferentes.

Muito além de um texto tradicional, que também é uma interface com mundos imaginários e concretos, os jogos são resultados de escrituras altamente sofisticadas que demandam conhecimento de muitas outras áreas. A psicologia e as ciências cognitivas estão entre as disciplinas mais importantes para 0 desenvolvimento de uma autoria eficiente que possa ser, para seus usuários, gratificante psicologicamente e recompensadora cognitivamente. Assim como a literatura, o teatro e o cinema, os jogos digitais têm como objetivo provocar emoções. Diferentemente das linguagens expressivas em que o espectador tem um papel de observador, podendo apenas interpretar e sentir, nos jogos digitais seu papel é ativo, participando efetivamente do fenômeno vivido. Ele escolhe deliberadamente seu caminho de acordo com as possibilidades e restrições desenhadas e projetas pelo autor (game designer). McGonigal ressalta essa característica dos jogos digitais como formadora de cidadãos proativos. Diz que os jogos digitais provocam emoções positivas. Em uma afirmação metodologicamente contraditória a autora define jogos como um trabalho duro que nós escolhemos para nós mesmos. De fato há jogos em que 
o empenho do jogador pode durar dias, semanas ou meses. Sutton-Smith ${ }^{12}$ (2001, segundo McGonigal (2012)) ${ }^{13}$, diz que o oposto de "play" (brincar, jogar) não é trabalho, é depressão. De acordo com a autora, um dos achados mais comuns em pesquisas de ESM (Experience SamplingMethod) é que normalmente o que fazemos quando procuramos por "fun" (diversão, divertimento) é buscar atividades de relaxamento que são de certo modo levemente depressivas. Atividades como assistir televisão, ir ao shopping, comer chocolate entre outras, têm um viés negativo após sua execução. Ficamos menos motivados e menos engajados. Os jogos digitais como geradores de emoções positivas são um tipo de "hard fun" que nos deixa melhores do que quando começamos, de acordo com pesquisa ESM. Há ainda o sentimento de "fiero"14, que, de acordo com pesquisadores do Centro de Pesquisas Interdisciplinares Para Ciências do Cérebroem Stanford, seria algo como um sentimento de "sair da caverna e conquistar o mundo" - desafios que podemos superar, batalhas que podemos vencer e perigos que podemos derrotar. Sentimento que dispara picos neuroquímicos. Jogos digitais são oportunidades de focar nossas energias em algo que temos prazer de fazer. Isto confronta o sentimento de depressão. É um trabalho mental, colaborativo e criativo.

Um dos conceitos em que se fundamenta o design de jogos digitais, e de narrativas interativas de modo geral, é o conceito de fluxo (flow) criado por Mihaly ${ }^{15}$. O conceito de flow se caracteriza pela imersão total de um sujeito em uma atividade qualquer. Essa imersão é como se fosse um fluxo, que Mihaly descreve como "optimal experience". Para o autor , "flow" é:

\footnotetext{
${ }^{12}$ Sutton-Smith, Brian. Ambiguity of play.Cambridge: Harvard University Press, 2001

${ }^{13}[. .$.$] When we are depressed, according to the clinical definition, we suffer from two things: a$ pessimistic sense of inadequacy and a despondent lack of activity. If we were to reverse these two traits, we'd get something like this: an invigorating sense of our own capabilities and a invigorating sense of activity. There's no clinical psychological term that describes this positive condition. But it's a perfect description of the emotional state of gameplay.

${ }^{14}$ [...] Fiero, according to researchers at the Center for Interdisciplinary Brain Sciences Research at Stanford, is a emotion that first create a desire to leave the cave and conquer the world. HOEFT, FUMIKO, et al. Gender Differences in Mesocorticolimb System During Computer Game Play. Journal of Psychiatric Research, v. 42, n. 4, March 2000. pp. 253-8.

http://spnl.stanford.edu/publications/pdfs/Hoeft_2008JPsychiatrRes.pdf

${ }^{15}$ MIHALY, Csikszentmihalyi. Flow. The Psychology of optimal experience. USA: HarperCollins e-Books, 1990.
} 
I develop a theory of optimal experience based on the concept of flow the state in which people are so involved in an activity that nothing else seems to matter; the experience itself is so enjoyable that people will do it even at great cost, for the sheer sake of doing so. (MIHALY, 1990, Posição 657 de 6255)

Em uma entrevista para a revista Wired ${ }^{16}$. Mihaly descreve flow como:

É estar completamente envolvido em uma atividade por si mesma. O ego desaparece. O tempo voa. Cada movimento ação ou pensamento segue o antecedente, como tocar jaz. Todo o seu ser está envolvido e você desenvolve suas habilidades ao máximo (tradução nossa).

O estado de fluxo contempla as seguintes características:

- Maximização da atenção diante de objetivos claros e deliberadamente escolhidos

- Envolvimento em resolução de problemas que não podem ser difíceis nem fáceis, pois se forem fáceis implicam desânimo ou tédio e se forem difíceis implicam em ansiedade. Ou seja, devem ser adequados às habilidades e capacidades atuais dos usuários.

- Exigência de concentração e foco.

- Ordenamento da consciência perseguindo objetivos realistas. Consciência como ordenamento intenciona da informação.

- Recompensa psicológica/emotivas.

- Sentimento de estar no controle da situação. ${ }^{17}$

- Feedback do sistema com correção de eventuais falhas ou desacertos.

- Desejo de permanência no estado de fluxo.

- Sensação de euforia ou profunda sensação de gozo, prazer ou satisfação.

- Sentimento de realização criativa.

\footnotetext{
${ }^{16}$. Disponível em <http://www.wired.com/wired/archive/4.09/czik pr.html>. Acesso em: 07 ago. 2013

${ }^{17}$ Yet we have all experienced times when, instead of being buffeted by anonymous forces, we do feel in control of our actions, masters of our own fate. On the rare occasions that it happens, we feel a sense of exhilaration, a deep sense of enjoyment that is long cherished and that becomes a landmark in memory for what life should be like. (MIHALY, 1999)
} 
- Suspensão da sensação de tempo e espaço.

- Perda da identidade - total envolvimento com a atividade.

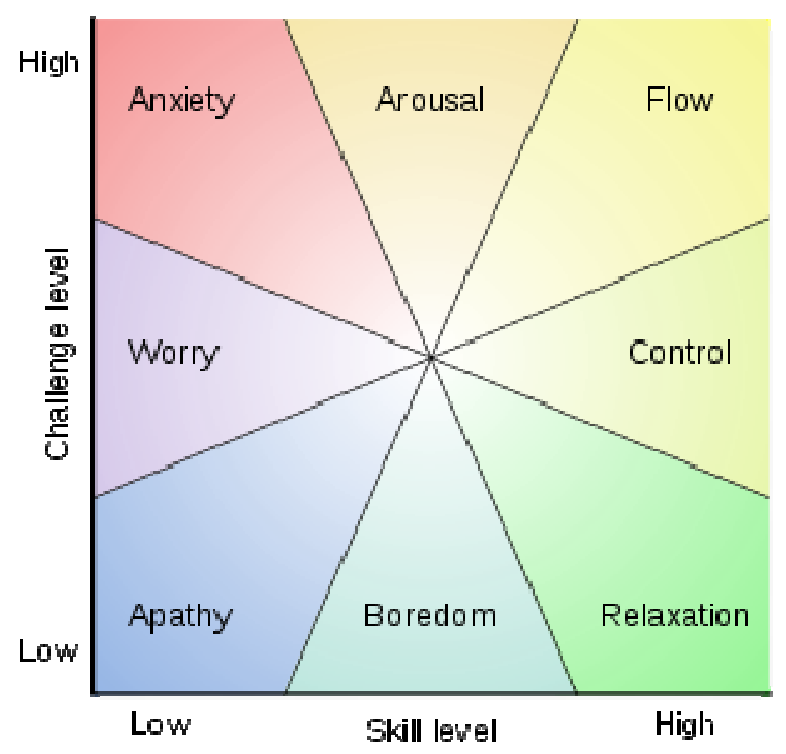

Fig. 01 - Estados mentais de acordo com a relação de níveis de desafios e níveis de habilidades. De acordo com o modelo de Csikszentmihalyil. Disponível em: $<$ http://en.wikipedia.org/wiki/Mihaly Csikszentmihalyi>.

É interessante notar que a partir do gráfico poder-se-ia representar o estado de fluxo como um campo vetorial de forças psíquicas cuja resultante apontasse na direção de pi/4 a partir do centro do gráfico. O design de jogos interessante deve levar em conta cada evento do jogo para que o usuário espectador não se desvie para os estados de ansiedade e relaxamento, fato que significaria 0 abandono do jogo por um dos dois motivos. Evidentemente que a curva de flow é diferente para usuários diferentes.

McGonigal se refere a esse estado de flow como um estado do qual o jogador não deseja sair, ele deseja permanecer. Vencer ou sair são eventos insatisfatórios. "Games are an obvious source of flow. [...] and play is the flow experience par excellence" (MIHALY (1999), op. cit. Segundo McGonigal, posição 616 de 7154 .). Dille \& Platten $\left(2007\right.$, p.2) ${ }^{18}$ chamam a atenção para 0 fato de que se alguém quiser criar conteúdo para um meio interativo, como

\footnotetext{
${ }^{18}$ DILLE, Flint \& PLATTEN, John Zuur. The Ultimate Guide to Video Game Writing and Design. USA: Skip Press, 2007.
} 
games, é necessário que se tenha em mente as expectativas do usuário de controlar o jogo e de este estar imerso, ou engajado.

Interatividade e interface com feedback são estruturas de linguagem fundamentais no desenvolvimento de cibertextos, narrativas interativas e jogos digitais. A capacidade de mudança do sistema por parte do usuário o coloca ao mesmo tempo como um leitor e escritor de uma obra em processo. Os ganhos em estratégias pedagógicas de sistemas de bons jogos digitais são evidentes, tendo em vista as argumentações de Mihaly e McGonigal. Podemos dizer o mesmo para obras cujo objetivo é estético.

Um dos fatos relevantes em sistemas como os jogos digitais é que pode haver uma adequação entre as habilidades do interator e o próprio sistema, que interpreta os eventuais erros e acertos do usuário. De acordo com Meadows ${ }^{19}$ (2003) o escritor e o game designer são de, algum modo, construtores de interfaces e potencialidades textuais. A interface utiliza signos, metáforas e códigos. Assim também são o jogo digital e o livro tradicional. Entretanto há diferenças significativas entre as narrativas ${ }^{20}$ convencionais e as narrativas interativas. Meadows define narrativas interativas como uma narrativa na qual alguém outro que não o autor da obra pode afetar, escolher e mudar o "plot" das ações. Isto muda os papeis, tanto do autor quanto do leitor. Brenda Laurel, segundo Meadows (op. cit. posição 729 de 5712) afirma que: "a narrativa interativa mais engajadora [imersiva] é aquela embasada no "flow" [fluxo], ou seja, uma participação sem interrupção na ação que se desenvolve. Um design pobre de interação pode interromper o fluxo e degradar a experiência." Meadows faz uma distinção entre interação e interatividade para diferenciar as relações entre humanos e entre humanos e computadores. Interatividade, palavra chave nos meios digitais, é descrita pelo autor como tendo 3 princípios fundamentais:

1) input output;

\footnotetext{
${ }^{19}$ MEADOWS, Mark Stephen.Pause \& Effect.The Arte of Interactive Narrative.USA: New Riders, 2003.

${ }^{20}$ Meadows (op. cit.) considera narrativa no contexto da origem da palavra que é "narrare", que por sua vez vem do indo-europeu "gnarus" que significa conhecer.
} 


\section{2) inside/outside;}

3) open/closed.

Os sistemas humano-computacionais que produzem narrativas interativas precisam de entradas e saídas que tenham um período de latência que não seja grande demais para que não se estabeleça uma relação de causa e efeito. Por exemplo, se um sujeito clica em um item de interface, ele espera que algo aconteça e que o retorno se dê num tempo em que ele possa perceber que sua ação resultou em uma ação do sistema. O segundo princípio é a relação entre as mudanças que ocorrem dentro e fora da mente ("inside/outside/the skull"). São alterações na imaginação do interator, seu mundo mental interno, e alterações empiricamente e sensorialmente detectáveis no mundo externo. Por exemplo, se em um jogo de tiro alguém puxa o gatilho, a resposta pode ser uma tremida nos controles (joysticks). Esses sistemas podem ser abertos ou fechados no sentido de possibilitar mais ou menos a intervenção/criação por parte do usuário. A adequação entre o desenho de possibilidades criado pelo escritor/designer e as ações do interator/coautor é que podem viabilizar uma experiência de fluxo: máximo de atenção, "trabalho duro", retorno psicológico positivo, desejo de permanecer no estado de fluxo. Como sugere Meadows, a adequação entre as duas esferas criativas (mundo do designer e mundo do interator) tem quatro passos: observação, exploração, modificação e mudança recíproca. A ideia de mudança recíproca ressalta a diferença entre os livros digitais e os convencionais. Por mais que se leia um livro na sua constituição física tradicional seu conteúdo não irá mudar nem dialogar com o leitor. Apenas a mudança "inside/skull" ocorrerá. Nos livros digitais, mais propriamente nos jogos, a mudança se reflete na apresentação física dos mundos "virtuais" nos quais podem ser observadas mudanças sonoras, visuais e de outras modalidades.

Diferença significativa entre os livros impressos tradicionais e os mundos virtuais reside na característica da conectividade informacional digital. Livros convencionais somente podem alterar conteúdos mentais, não o substrato físico midiático de outros livros. Já em livros digitais, que podem "carregar" 
narrativas interativas, a interação em um livro pode proporcionar a mudança em outro. Hiperlinks podem ser criados entre livros e obras digitais diferentes. Os websites são exemplos claros de como isso ocorre na rede. Os livros digitais também podem ser conectados a sistemas de computação física, ou seja, as interações podem acontecer de acordo com inputs e outputs de sensores e atuadores eletrônicos. Um joystick, por exemplo, funciona como um sensor que detecta os movimentos do usuário e os converte em sinal digital para o sistema que pode dar resposta (feedback) apresentando, por exemplo, uma imagem apresentada na tela, ou mesmo fazendo o joystick tremer. A interatividade cresce na medida em que o texto (sentido largo) projetado pelo designer demanda estruturas conexas interligadas. $O$ estado da arte dos jogos digitais inclui dispositivos físicos, que ultrapassam as potencialidades interativas e comunicativas muito além das antigas metáforas das interfaces gráficas (GUI - Graphic User Interface) tão bem sucedidas nos desktops até os dias de hoje. Sensores como o Kinect da Microsoft pode captar movimentos, reconhecer fala e localizar fontes de áudio espacialmente. Hoje, com a inclusão na pauta criativa dos jogos e ambientes de aprendizagem digital estão os softwares e hardwares livres. Iniciativas como Arduino, Processing, Open frameworks, Puredata, RaspberryPi entre tantas outras fazem expandir o modo como podemos criar jogos, narrativas interativas e ambientes imersivos de aprendizagem. Sullivane $\operatorname{lgoe}^{21}$ (2004) caracterizam a visão ordinária dos computadores pelos seus usuários como: tela, teclado, mouse, elementos comuns de interatividade. Segundo os autores a visão ordinária que os computadores têm de seus usuários pode ser vista na figura que segue.

${ }^{21}$ O'SULLIVAN, Dan e IGOE, Tom. Physical Computing. Sensing and Controlling the Physical World with Computers. Boston: Thomson, 2004. 


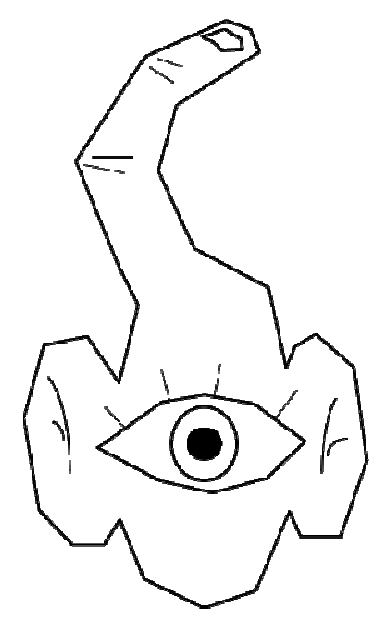

Os autores preferem o termo computação a computadores e investem no conceito de computação física como novas formas de interfaces com o mundo.

\footnotetext{
Now we need to make computers for rest of you. "We need computers that respond to the rest of your body and the rest of the world. GUI technology allows you to drag and drop, but it won't notice if you twist and shout". (Sullivan e Igoe, 2004 p.XVII).
}

A partir dessas características descritas, podemos inferir a enorme potencialidade pedagógica dos jogos digitais e das narrativas interativas de uma maneira geral. Possibilidade de articular salas de aulas interativas, livros adaptáveis às necessidades de cada aluno, participação ativa, multimodalidade e contato físico, liberdade de ação, entre outras possibilidades de estratégias pedagógicas, permitem ao aprendiz/produtor de conhecimento assumir uma atitude positiva e construtiva de modo colaborativo. Devemos lembrar também que leitores/usuários portadores de necessidades especiais podem se beneficiar dessas tecnologias de comunicação e informação.

Interação, como o nome diz, requer uma ação articulada entre dois sistemas, falamos especialmente dos sistemas usuário computador ou mesmo vários usuários ligados a vários sistemas computacionais. Ler, no contexto dos sistemas aos quais estamos nos referindo, é agir, inclusive fisicamente. Se as escritas informacionais que fundamentam os games e as narrativas interativas demandam esforço por parte dos designers e grupos de produção, o mesmo pode ser dito, embora sob uma ótica diferente, dos usuários/leitores. 
Espen J. Aarseth ${ }^{22}$ (1997) fala de uma literatura ergódica na qual o leitor de cibertextos é um "player" (no sentido múltiplo da palavra: jogador, ator e brincador) do qual é demandado esforço para explorar os mundos virtuais. $\mathrm{O}$ termo ergódico tem seu significado construído pelas palavras gregas "ergon" e "hodos", que significam trabalho e caminho. O prazer do jogador digital não é aquele de um leitor convencional, este último é um leitor voyeur que se situa confortavelmente em um lugar seguro, mas impotente. O leitor de cibertextos é um leitor engajado e imerso em situações nas quais a história depende de sua ação e sua ação constrói a história. Os jogos digitais estão entre os mais difundidos cibertextos. McGonigal (op. cit.) circunscreve conceitualmente a enorme variedade de jogos digitais a quatro traços fundamentais: objetivos, sistema de regras, sistema de feedback e participação voluntária (atividade que traz recompensa psicológica). Bernard Suits, (segundo McGonigal, posição 392 de 7154) define jogos como tentativa voluntária de ultrapassar obstáculos desnecessários (tradução nossa). Como Aarseth, a autora levanta as características positivas de um trabalho duro voluntário e recompensador.

Diferentemente das narrativas não interativas, o jogador se vê envolvido em descobrir caminhos, resolver problemas dentro de uma estrutura topológica que existe fora de sua mente. O estatuto ontológico dos mundos virtuais dos jogos digitais é garantido por uma experiência intersubjetiva entre jogadores que vivenciam fenomenologicamente os mundos construídos.

Para Aarseth, a característica de um texto ser ergódico não é o seu suporte de apresentação, mas a mecânica do texto, a máquina geradora de possibilidades de caminhos, conflitos, problemas e soluções. Sylvester ${ }^{23}$ (2013) fala de motores de experiência. Para esse autor os jogos são compostos de mecânicas que definem como o jogo funciona. Um jogo de xadrez, por exemplo, não é muita coisa sem suas regras de funcionamento, ou seja, não basta apenas peças bonitas e um campo quadriculado sobre o qual elas são postas. Seu valor, portanto, não está fundamentalmente nas estruturas visuais,

\footnotetext{
${ }^{22}$ AARSETH, Espen J. Cybertext. Perspectives on Ergodic Literature. Baltimore: The John Hopkins University Press, 1997.

${ }^{23}$ SYLVESTER, Tynan. Designing Game. A Guide to Engeneering Experiences. Beijing: O'Reilly, 2013.
} 
táteis, sonoras etc., mas antes no "game design". O conjunto de regras estabelece as potencialidades e as restrições do sistema. Gorp (op. cit.) se refere a "affordances" como aquilo que o produto é capaz de fazer. O conjunto de regras em narrativas interativas computacionais é uma espécie de texto fundamental dento do texto jogo. Para Sylvester, o game designer (o escritor dos tempos digitais) tenta costurar histórias e regras dentro de um sistema integrado capaz de produzir significação e sentido. Game design não está no código, na arte, nos sons, nas imagens e peças. Game design significa um "artesanato", uma construção de regras que fazem todas essas peça ganharem vida. De outro modo que não das narrativas tradicionais, a autoração nos jogos digitais não se dá por uma sistematização, no tempo e no espaço, de eventos (ou plots) relacionados por causalidades e consequências, mas antes por um sistema gerador de eventos que são criados durante o jogo. Esses eventos são disparados por processos internos à máquina do jogo ou por interação do usuário. Para terem significados, tais eventos devem provocar algum tipo de emoção e para provocar emoção deve haver alguma relação com a mudança de expectativas sobre valores humanos. Há um ciclo grande de feedbacks no que deve ser previsto no processo de escrita e que deve ser explorado pelo usuário no processo de "leitura".

A ideia de fluxo (flow) lança luzes sobre o motivo das crianças, jovens e adultos contemporâneos passarem tanto tempo de suas vidas dedicando-se a essas atividades nos mundos digitais, nos quais a realidade são os jogos, simulações e novos mundos impossíveis na concretude fenomênica da dita "realidade mesma". É possível vislumbrar o distanciamento das escolas e livros tradicionais usados nos moldes atuais em relação às práticas imersivas dos aprendizes digitais. $O$ fenômeno é mundial. Entretanto, é possível perceber que há uma tendência crescente do olhar para as narrativas digitais como uma forma extremamente enriquecedora da experiência de produção de conhecimento e de vivência estética. 
No campo da alfabetização e letramento, Ribeiro ${ }^{24}$ (2003) fala sobre os Parâmetros Curriculares Nacionais que estabeleceram normas e padrões para garantir que o ensino da língua materna deve conter uma variedade de gêneros textuais, literários ou não, verbais ou não-verbais de modo a contextualizar uma série de empregos em várias atividades sociais que demandam diferentes abordagens textuais. A expansão de gênero, meio e forma dos textos, instrumentalizados pela técnica e pela aquisição do código deve absorver as mudanças ocorridas na sociedade as quais são refletidas na amplitude do modo como construímos informação e do modo como nos comunicamos. A autora argumenta que o professor e o autor precisam se pautar também nas novas tecnologias de inteligência incluindo nelas os jogos eletrônicos que favorece o aprendizado por meio de simulação.

Uma das particularidades narrativas digitais interativas reside na distância, ou esforço, que existe entre o processo de produção (escrita) e o processo de uso (leitura). O fenômeno do distanciamento dos processos de leitura e escrita ocorre hoje em grau muito mais acentuado do que ocorreu no passado. Quando se fala de distanciamentos que também ocorreram no passado tomase como exemplo eloquente a passagem da oralidade à escrita. Com a instrumentalização da escrita um novo hiato emergiu entre leitores e simplesmente ouvintes. Foi necessária a aprendizagem de um código mediador entre os interlocutores. Quando a civilização ultrapassou a oralidade como "a" forma de comunicação e expressão, as especificidades de um discurso regido eminentemente pela fala cederam lugar a códigos que deveriam ser apreendidos pelos interlocutores que passaram a usar as tecnologias de escrita e leitura. A memória dos sujeitos de fala, que haviam representado um papel singular na transmissão do conhecimento, cede lugar à memória física fora da mente: a memória midiática, o códex. Formas de organização do pensamento, que giravam em torno de recuperações mentais de fatos, dados, acontecimentos e conhecimentos passam a se valer de uma tecnologia que armazena tudo isso fora da memória individual. Processos mnemônicos que utilizavam recursos mentais cedem espaço para novas formas de cognição.

${ }^{24}$ RIBEIRO, Ana Elisa. Textos e hipertextos na sala de aula. In: COSCARELLI, Carla Viana. Novas Tecnologias, novo textos, novas formas de pensar. Belo Horizonte: Autêntica, 2003.

Texto Digital, Florianópolis, v. 10, n. 1, p. 138-162, jan./jul. 2014. ISSNe: 1807-9288 
Não menos importantes ou diferentes são os processos de mudança cognitivos suportados por tecnologias de leitura e escrita digitais. Tecnologias sobre as quais a sociedade contemporânea se fundamenta na construção, difusão e armazenamento de conhecimento. Acreditamos haver um fosso enorme entre produzir um texto, ou hipertexto digital (software) capaz de ser relevante socialmente (ideia de letramento, por exemplo) e as habilidades de ler tais textos em ambientes digitais como computadores pessoais, por exemplo. Não basta saber utilizar mouse, teclado, navegar na web e algumas outras habilidades e capacidades corriqueiras para que alguém se torne um escritor de textos digitais (hipermídia, hipertexto, games, narrativas interativas etc.). É necessário e imperativo dominar o código computacional, o conhecimento de suas linguagens e processos internos.

Esta ruptura de estratégias cognitivas impõe metodologias e propostas pedagógicas altamente diferenciadas. Prensky (op. cit.) chama a atenção sobre a mudança ocorrida nos alunos e sobre a sua inadequação aos sistemas educacionais atuais. Enquanto leem cinco5 horas, jogam 10 mil horas durante o percurso de suas vidas até a graduação. Os nativos digitais adotam modelos de pensamento diferentes. Os dados são de 2001. Se consultarmos fontes mais atualizadas, já anteriormente citadas por McGONIGAL, percebemos 0 peso dos números. A realidade de nossas escolas, professores e alunos é eloquente bastante para nos mostrar o quão longe estamos de usar essa "tecnologia" de produção de conhecimento de modo eficiente. Entendo eficiência em um sentido mais abrangente que inclui a construção da ideia de "fluxo" defendida por Mihaly.

A experiência do usuário, e mesmo do desenvolvedor-escritor-designer, de viver os mundos digitais interagindo, mudando os rumos da narrativa, construindo com os autores novas possibilidades está longe de ser uma atividade como a leitura em seu sentido tradicional e trivial. É fato que quanto mais as tecnologias de informação se desenvolvem, mais a escrita se torna complexa e a leitura, ao contrário, mais fácil. Para perceber essa afirmativa basta pensar em games e aplicativos educacionais, para crianças na faixa de pré-alfabetização. As interfaces têm que ser intuitivas e os aplicativos precisam 
ser produzidos (escritos) por equipes que têm elevado índice de conhecimento multidisciplinar pertinente ao mundo dos games digitais.

Não é fácil desenvolver estratégias narrativas para publicações dirigidas a um público nativo digital quando quem ainda está no comando das diretrizes e normas, que norteiam e julgam se um livro/game digital é bom ou ruim, é um imigrante digital que talvez nunca tenha passado pela experiência de um jogo digital. Escrever e ler em tempos digitais não é matéria sabida nem razoavelmente conhecida das áreas pedagógicas, artísticas, linguísticas, cognitivas entre outras. Engatinhamos nessa prática. Vivemos uma época de extremas transformações na nossa forma de articular informações sobre os mundos (reais ou virtuais) e mesmo da nossa forma de nos comunicar em meio a eles. Até mesmo o velho hipertexto ainda é motivo de discussões acaloradas e de perspectivas mais diversas. Talvez a característica mais marcante dos textos digitais (narrativas interativas e jogos digitais) resida no aspecto coletivo e colaborativo da produção, seja no "modo designer" ou no "modo player".

O autor contemporâneo de textualidades interativas em meio digital já parte da premissa que seu texto, mais do que uma perspectiva pura e simples, é um campo aberto que precisa da participação de um coautor. $O$ fato é que essa emergente textualidade coletiva implica mudanças de costumes, práticas e crenças, principalmente a crença de que o autor é um criador solitário, que inventa ex nihilo suas ideias (histórias e estórias), propriedades inabaláveis e intocáveis em sistemas políticos em que a colaboração, coletivização e distribuição livre do conhecimento sejam palavras proibidas.

\section{DIGITAL GAMES AND INTERACTIVE NARRATIVES: CONSIDERATIONS ON FORMS OF WRITING, READING AND IMMERSING}

ABSTRACT: This article seeks to raise some considerations about, especially, interactive digital narrative texts and interactive digital games, which refers to the process of participatory production, mass access to these works on the Web and its importance to the field of education and art. The text covers transdisciplinary characteristics of digital writing processes, including flow concept advocated by Mihaly.

KEYWORDS: Digital Storytelling. Interactive Digital Books.Digital Games. Flow; Education, Art and Entertainment. 


\section{REFERÊNCIAS}

AARSETH, Espen. Cibertext.Perspectives on Ergodic Literature. Maryland: John Hopkins University Press, 1997.

CASTI, John L. Mundos Virtuais. Como a computação está mudando as fronteiras da ciência. Rio de Janeiro: Revam, 1997.

CASTRONOVA, Edward. Exodus to the Virtual World. New York: Palgrave Macmillan, 2007.

DILLE, Flint \& PLATTEN, John Zuur. The Ultimate Guide to Video Game Writing and Design. USA: Skip Press, 2007.

GEE, James Paul. What video games have to teach us about learning and literacy. USA: Palgrave Macmillan, 2004.

. The Anti-education Era. Creating Smarter Students Through Digital Learning. USA: Palgrave Macmillan, 2013.

GORP, Trevor van \& ADAMS, Edie. Design for emotion. Waltham: Morgan Kaufmann, 2012.

LÉVY, Pierre. Cibercultura. São Paulo: Editora 34, 2000.

As Tecnologias da Inteligência. O Futuro do pensamento na era da informática. São Paulo: Editora 34, 1993

MCGONIGAL, Jane. The Reality is Broken. Why Games Make us Better and How They Can Change The World. New York: Penguin Press, 2012.

MEADOWS, Mark Stephen. Pause \& Effect. The Arte of Interactive Narrative.USA: New Riders, 2003.

MIHALY, Csikszentmihalyi. Flow. The Psychology of optimal experience. USA: HarperCollins e-Books, 1990.

Miller, Caroline Handler. Digital storytelling. A Creator's Guide to Interactive Entertainment. USA, Focal Press, 2004.

O'SUlLIVAN, Dan e IGOE, Tom. Physical Computing. Sensing and Controlling the Physical World with Computers. Boston: Thomson, 2004.

REAS, Casey. Form + Code in design, art and architeture. A guide to Computational Aesthetics. New York: Princeton Architectural Press, 2010.

RIBEIRO, Ana Elisa. Textos e hipertextos na sala de aula. In: COSCARELLI, Carla Viana. Novas tecnologias, novos textos, novas formas de pensar. Belo Horizonte: Autêntica, 2003. 
RYAN, Laure Marie (Org.) Narrative Across Media. The Language of Storytelling. Lincin: University of Nebraska Press, 2004.

PRENSKY, Marc. Digital Natives, Digital Immigrants. NCB University Press, Vol. 9 No. 5, October 2001. Disponível em $<$ http://www.nnstoy.org/download/technology/Digital\%20Natives\%20\%20Digital\%20Immigrants.pdf>. Acesso em: 05 ago. 2013.

SYLVESTER, Tynan. Designing Game. A Guide to Engeneering Experiences. Beijing: O'Reilly, 2013.

SUTTON-SMITH, Brian. Ambiguity of play. Cambridge: Harvard University Press, 2001.

Texto recebido em: 14/07/2014. 